Л. І. Лєві, О. С. Зима

Національний університет «Полтавська політехніка імені Юрія Кондратюка», Полтава, Україна

\title{
СУЧАСНІ ІНТЕЛЕКТУАЛЬНІ МЕТОДИ МОДЕЛЮВАННЯ СКЛАДНИХ ТЕХНОЛОГІЧНИХ ОБ'ЄКТІВ
}

\begin{abstract}
Анотація. Одним з ключових питань синтезу систем автоматичного регулювання є розробка адекватних математичних моделей об'єктів керування. Розробка моделей фізичних систем - це дуже складна і трудомістка робота, яка займає від 80 до 90 \% зусиль, необхідних для аналізу і синтезу систем керування, і включає такі етапи: визначення параметрів процесу, які впливають на об'єкт керування; визначення зв'язків між параметрами; складання матеріальних та енергетичних балансів об'єктів керування; лінеаризація цих балансів; одержання диференціального рівняння. Результатом моделювання майже всіх технологічних об'єктів є складне диференціальне рівняння великого порядку, яке надалі використовується для розрахунку систем автоматичного регулювання. Під математичною моделлю зазвичай розуміють сукупність співвідношень (рівнянь, логічних умов, операторів тощо), що визначають характеристики станів об'єкту моделювання. Сучасні наука й технологія як об'єкти дослідження розглядають матеріальні об'єкти навколишнього світу та їхні фізико-хімічні перетворення. Практична реалізація цих досліджень від лабораторних установок до промислових виробництв використовує моделювання як процес пізнання, а також для оптимальної організації, функціонування й керування виробництвом. Сучасним технологіям притаманна висока складність, яка виявляється у великій кількості й різноманітті параметрів, що визначають хід процесів, внутрішніх зв'язків між параметрами, у їхньому взаємному впливі, причому зміна одного параметра може викликати нелінійну зміну інших параметрів. Ця складність підсилюється при виникненні множинних зворотних зв'язків між параметрами, а також неконтрольованими збуреннями, випадковим чином розподіленими в часі. Інформаційний потенціал, генерований технологічними процесами, надзвичайно великий. При обмежених можливостях його сприйняття необхідно зменшувати цей потенціал, що остаточно призведе до скорочення альтернатив під час прийнятті керуючих рішень. Це досягається пізнанням процесу через моделі - спрощені системи, які відображають окремі, обмежені в потрібному напрямку, сторони процесу, що розглядається. Існує багато способів одержання моделей технологічних процесів. Кожен спосіб дає можливість побудувати модель, адекватну процесу в певному сенсі, що залежить від обраного критерію. Це означає, що існує деяка абстрактна відповідність між безліччю моделей і модельованим об'єктом. Моделювання, власне кажучи, засновано на використанні динамічної аналогії, яка означає нетотожну подобу властивостей або співвідношень.
\end{abstract}

Ключов і слова : детерміновані моделі стохастичні моделі, структурна ідентифікація, параметрична ідентифікація, пасивний експеримент, активний експеримент.

\section{Вступ}

Постановка проблеми. Одним з ключових питань синтезу систем автоматичного регулювання $\epsilon$ розробка адекватних математичних моделей об'єктів керування. Розробка моделей фізичних систем - це дуже складна і трудомістка робота, яка займає від 80 до $90 \%$ зусиль, необхідних для аналізу і синтезу систем керування, і включає такі етапи [1]:

визначення параметрів процесу, які впливають на об'єкт керування; визначення зв'язків між параметрами;

складання матеріальних та енергетичних балансів об'єктів керування; лінеаризація цих балансів;

одержання диференціального рівняння.

Результатом моделювання майже всіх технологічних об'єктів $є$ складне диференціальне рівняння великого порядку, яке надалі використовується для розрахунку систем автоматичного регулювання. Під математичною моделлю зазвичай розуміють сукупність співвідношень (рівнянь, логічних умов, операторів тощо), що визначають характеристики станів об'єкту моделювання.

Сучасні наука й технологія як об'єкти дослідження розглядають матеріальні об'єкти навколишнього світу та їхні фізико-хімічні перетворення. Практична реалізація цих досліджень від лабораторних установок до промислових виробництв використовує моделювання як процес пізнання, а також для оптимальної організації, функціонування й керування виробництвом.

Аналіз останніх досліджень і публікацій. Сучасним технологіям притаманна висока складність, яка виявляється у великій кількості й різноманітті параметрів, що визначають хід процесів, внутрішніх зв'язків між параметрами, у їхньому взаємному впливі, причому зміна одного параметра може викликати нелінійну зміну інших параметрів. Ця складність підсилюється при виникненні множинних зворотних зв'язків між параметрами, а також неконтрольованими збуреннями, випадковим чином розподіленими в часі [2 - 9]. Інформаційний потенціал, генерований технологічними процесами, надзвичайно великий. При обмежених можливостях його сприйняття необхідно зменшувати цей потенціал, що остаточно призведе до скорочення альтернатив під час прийнятті керуючих рішень. Це досягається пізнанням процесу через моделі - спрощені системи, які відображають окремі, обмежені в потрібному напрямку, сторони процесу, що розглядається. Існує багато способів одержання моделей технологічних процесів. Кожен спосіб дає можливість побудувати модель, адекватну процесу в певному сенсі, що залежить від обраного критерію. Це означає, що існує деяка абстрактна відповідність між безліччю моделей і модельованим об'єктом. Моделювання, власне кажучи, засновано на використанні динамічної аналогії, яка означає нетотожну подобу властивостей або співвідношень. 
Формулювання мети статті. Моделювання передбачає побудову моделі будь-якого характеру, що має властивості (або характеризується співвідношеннями), подібні до властивостей або співвідношень досліджуваної природної або технічної системи. Таким чином можна імітувати роботу системи й приймати попередні рішення щодо оптимізації ії характеристик. До мети моделювання можна віднести:

- обгрунтування вірогідності математичного описання;

- одержання функціональних зв'язків між величинами;

- порівняння кінцевого числа стратегій рішення індивідуальної проблеми;

- ідентифікація системи, яку моделюють;

- оптимізація моделі;

- вибір цільових функцій;

- застосування моделювання для навчання й тренування.

\section{Основна частина}

Дослідження методом моделювання варто починати 3 розробки моделі й продовжувати в ході роботи з нею. Мета такого дослідження - визначення поведінки досліджуваної системи. Практично не існує обмежень щодо характеру системи. Предметом нашого вивчення $є$ різноманітні технологічні системи [1]. Моделювання систем поєднує в собі моделі об'єкта 3 одного боку й способи відображення їх функціонування 3 іншого. I чим глибше цей взаємозв'язок відображено в моделі, тим кращий результат можна очікувати від моделювання. При цьому моделі повинні найбільш точно відповідати методам і цілям моделювання.
Умови, що накладаються цілями моделювання, визначають методи й критерії класифікації моделей.

Можливі методи створення моделей відображено на рис. 1.

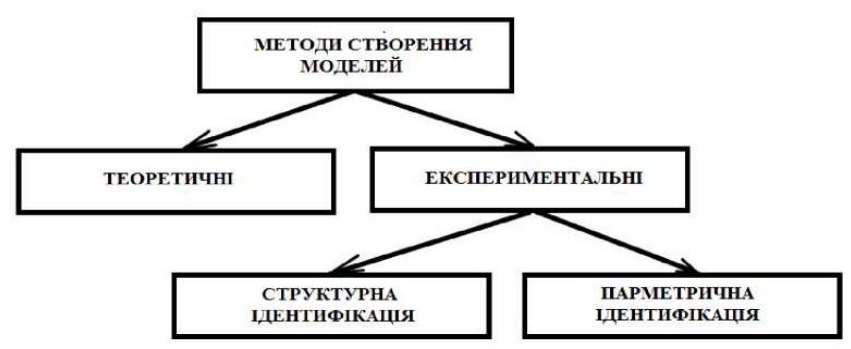

Рис. 1. Методи створення моделей

Теоретичний - припускає створення моделі на основі відомих законів фізики, механіки, які описують основні, з погляду поставленої мети, процеси, що відбуваються в об'єкті. Експериментальний (або ідентифікація) - припускає побудову моделі на основі результатів експерименту, проведеного 3 реальним об'єктом. Своєю чергою експериментальний метод побудови моделі можна розділити на такі різновиди.

- структурну ідентифікацію, за допомогою якої визначається структура моделі на підставі результатів експерименту, проведеного 3 реальним об'єктом;

- параметричну ідентифікацію, за допомогою якої визначаються параметри моделі, структура якої визначена раніше, на підставі результатів експерименту, проведеного з реальним об'єктом.

Можна виділити такі види моделей, які показані на рис. 2.

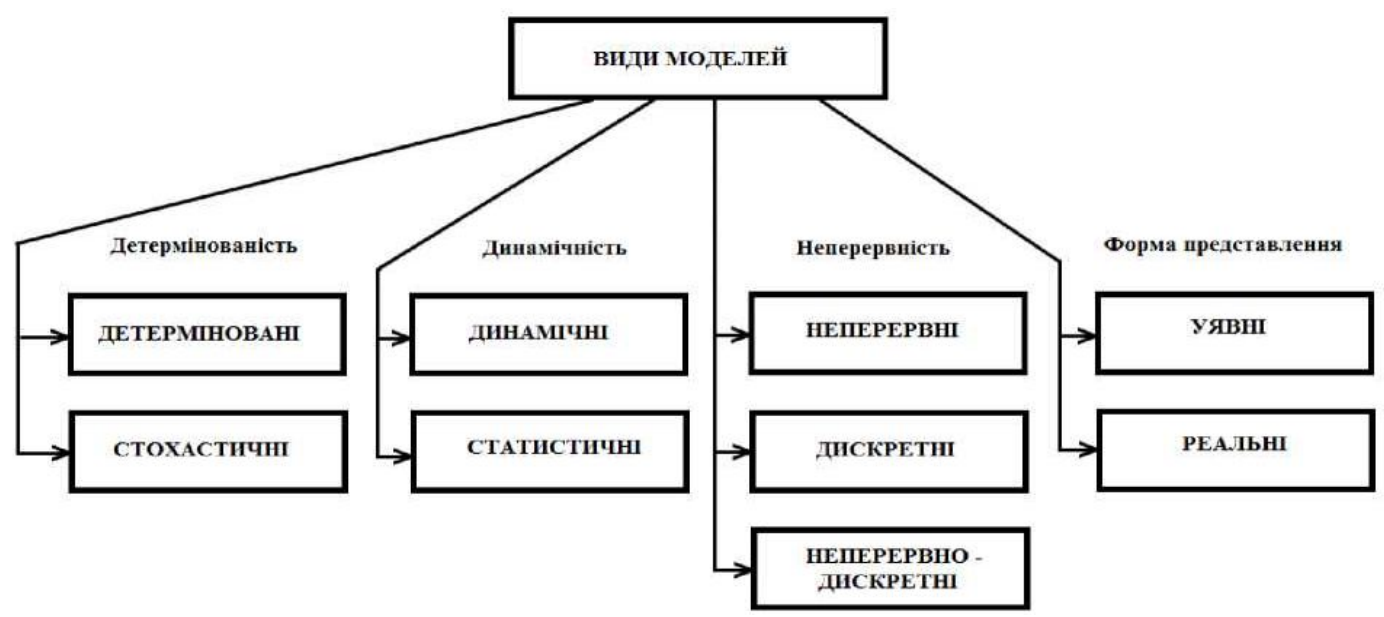

Рис. 2. Види моделей

Залежно від характеру досліджуваних (модельованих) процесів моделі можна класифікувати за такими ознаками. Детерміновані моделі, у яких використовуються детерміновані залежності без урахування внутрішніх факторів і впливів зовнішнього середовища, що носять випадковий характер. Стохастичні моделі, які відображають імовірнісні й випадкові процеси в об'єкті. При цьому використовується математичний апарат статистики й імовірнісних процесів. Статичні моделі - це моделі, які відображають особливі статичні режими, коли процеси, що відбуваються в об'єкті, не залежать від часу. Динамічні моделі - це моделі, які відображають процеси, що відбуваються в об'єкті, в часі. При цьому час $є$ одним 3 параметрів моделі. Неперервні моделі - це моделі, які відображають зміну параметрів процесів, що відбуваються в об'єкті, протягом усього часу дослідження й (або) уздовж координат об'єкта безперервною залежністю. Математичним апаратом даного типу моделей $є$ диференціальні 
рівняння. Дискретні моделі - це моделі, які відображають параметри процесів у певні моменти часу й (або) у певних точках об'єкта. Застосовуваний математичний апарат - різницеві рівняння. Неперервнодискретні моделі - це моделі, які поєднують у собі властивості безперервних i дискретних моделей. Наприклад, безперервна зміна параметрів у часі й дискретна - в просторі [1].

Процес розробки моделі включає такі етапи.

1. Постановка задачі й визначення властивостей реального об'єкта, що підлягають дослідженню.

2. Констатація складності або неможливості дослідження реального об'єкта.

3. Вибір моделі, що добре фіксує основні властивості об'єкта з одного боку, і що легко піддається дослідженню з іншою. Модель повинна відображати основні властивості об'єкта й не повинна бути громіздкою.

4. Дослідження моделі відповідно до поставленої мети (проведення експериментів).

5. Перевірка адекватності об'єкта й моделі. Якщо немає відповідності, то необхідно повторити перші чотири етапи.

6. Остаточний вибір моделі.

Кожний 3 етапів $є$ дуже важливим для отримання адекватної моделі. Однак необхідно приділити особливу увагу 4-му етапу. Проведення експериментів є складним етапом, часто довготривалим, а можливо й небезпечним. Застосування складного обладнання або устаткування, що знаходиться у промисловому використанні, робить цей етап досить коштовним. Тому проведення етапу експериментальних досліджень необхідно ретельно планувати та готувати.

За способом проведення експериментальні дослідження можна поділити на такі види.

- Виробничий (пасивний) експеримент - це відтворення на натурному об'єкті основних режимів виробничого процесу для подальшого дослідження. В якості збурюючих впливів використовуються природні випадкові зовнішні та внутрішні збурення. Процес ведеться виключно в рамках технологічного регламенту, не наближаючись до небезпечної межі.

- Науковий (активний) експеримент - це відтворення на натурному об'єкті якісно нових режимів, збільшення технічних границь. Реальний об'єкт використовується в якісно нових умовах функціонування або при впливі нових чинників зовнішнього середовища 3 подальшим обробленням результатів. Збурення вносять примусово за попередньо розробленою програмою. Такий підхід вимагає ретельної підготовки та планування.

- Комплексний експеримент - поєднує в собі елементи наукового й виробничого експериментів.

За способом відтворення процесів на моделях (моделювання) можна виділити такі види:

- моделювання у реальному масштабі часу здійснюють постановку експерименту в однакових масштабах часу як для об'єкта, так і для моделі;

- моделювання у нереальному масштабі часу - при постановці експерименту масштаби часу для моделі й об'єкта різняться на деяку величину.
Можна виділити класичний і системний підходи до завдання побудови моделей. Суть методу полягає в тому, що реальний досліджуваний об'єкт розбивається на окремі компоненти і вибираються певні цілі формування окремих компонентів моделі. Потім, на основі вихідних даних, створюються компоненти моделі, сукупність яких, 3 урахуванням їх взаємодії, поєднується в модель. Даний метод $є$ індуктивним, тобто модель будується від окремого до загального (від окремих компонентів до повної моделі). Класичний підхід використовується для моделювання відносно простих систем [1].

Моделювання широко застосовується в процесі дослідження, проектування та створення систем керування технологічними процесами [1]. Моделювання як метод дослідження об'єктів і систем керування $є$ важливим етапом їх проектування. На основі розроблених моделей можна виконувати аналіз та синтез простих і складних систем керування, вирішувати питання їх оптимізації, а також прогнозувати якість роботи. У вітчизняній практиці слово «моделювання» відповідає англійському "Modelling" (або американському "Modeling"), тобто побудові моделі та іiі аналізу, включаючи оцінку адекватності. Англомовному "simulation" традиційно відповідає або «імітаційне моделювання» або «обчислювальний експеримент», тобто розробка комп'ютерної моделі й робота 3 нею. У той же час «обчислювальний експеримент» наявний у сучасній науці моделювання. Усі ці терміни насправді описують певний ряд технологічних операцій, які виконуються в процесі створення, верифікації й використання математичних моделей.

Говорячи про керування процесом моделювання, частіше використовують терміни стан (state), подія (event) і об'єкт (entity - буквально «сутність»). Відповідно до цього сам процес включає Event management, Queues management, Time management та Model management. Стан у моделюванні приблизно відповідає поняттю стану в теорії керування - це сукупність змінних моделі, що описують систему в кожний момент часу. Події - це дії, що призводять до зміни стану системи. Об'єкти - це дійсно сутності (об'єкти реального світу), представлені в моделі. Для них визначається стан, і на них спрямовані впливи.

Програма моделювання включає черговість подій (Event management, Queues management), у тому числі допускається й випадковий порядок подій. Time management визначає порядок урахування часу (у найпростішому випадку час тече рівномірно). У випадку моделювання декількох процесів, що відбуваються у різних масштабах часу, можна скористатися так званим Stepped simulation (покрокове моделювання). Model management описує взаємодію моделі 3 користувачем. Особливу роль в останні роки набув «дружній інтерфейс» (аудіовізуальне подання результатів моделювання, 3D-графіка). Крім того, у складних випадках Model management підтримує стійкість самого процесу моделювання, відслідковує закінчення певних стадій, одержання потрібного обсягу даних, перехід до наступних етапів процесу й визначає момент закінчення процесу. 
Одним з головних показників якості процесу розроблення моделі є iї адекватність. Під адекватністю моделі розуміють відповідність властивостей (функцій/параметрів/характеристик тощо) моделі i відповідних властивостей об'єкта, який досліджують за допомогою моделі [1]. Очевидно, що мінливість досліджуваного об'єкта робить поняття адекватності відносним. I з цього можна зробити висновок, що певна модель в деяких випадках може ідентифікуватися як адекватна, а в інших - як неадекватна. Залежить це від ступеня поінформованості про властивості об'єкта. Чим менше поінформованість, тим більше ймовірність отримати неадекватну модель. Про адекватність моделі як практичного інструмента треба судити не тільки й навіть не стільки по тому, наскільки близько математичний опис до фізиці реального життя. Може статися, що рекомендації й рішення, які отримані на основі деякої свідомо «неадекватної» моделі, задовольняють існуючим реальним потребам. У таких випадках більш адекватні моделі не розробляються зовсім, або залишаються непотрібними навіть будучи розробленими. Твердження про адекватність моделей у теорії й практиці керування передусім диктується розв'язуваною задачею. Інтегрована модель керування складною системою адекватна своій меті тільки тоді, коли вона дозволяє досягати поставлених цілей. Якщо деяка задача може бути розв'язана без строгої математичної моделі, наприклад, за допомогою «евристичних» рекомендацій, алгоритмів або рішень, то до реального моделювання об'єкта справа може й не дійти. Тому відсутність математичного опису парадоксальним чином можна вважати найпростішою «адекватною» моделлю процесу за відсутності самої необхідності в моделюванні. Адекватність моделі зв'язана тільки 3 можливістю іiі практичного використання. Будь-які явища, що виявлено в обчислювальному експерименті, вимагають підтвердження в реальному експерименті. Підтвердження адекватності моделі в принципі триває на будь-якому етапі роботи 3 моделлю. I робиться це саме порівнянням із практикою. Відмінність очікуваного за моделлю й реального ходу процесу вимагає уточнення моделі.

Ідентифікацією називається оптимальна в певному розумінні модель, яка побудована за результатами спостережень над вхідними та вихідними змінними об'єкта [10]. Задачею ідентифікації називається обернена задача системного синтезу. Виділяють два типи задач ідентифікації.

1. Структурна ідентифікація.

2. Параметрична ідентифікація.

Структурна ідентифікація - це складна задача, яка зазвичай потребує творчого підходу. Головна мета - визначення структури моделі. При цьому об'єкт розглядається як «чорна скринька», тобто інформація про його структуру відсутня. Для розв'язання задачі структурної ідентифікації можна запропонувати лише загальний алгоритм у вигляді певних рекомендацій.

1. Визначитися з типом (класом) моделі.

а) якщо можливо, будувати фізичну модель (за відомими законами фізики, пам'ятаючи про мету побудови моделі);

б) побудову математичної моделі треба починати 3 найпростіших типів (лінійна, безперервна, одномірна тощо);

в) намагатися перетворити модель до вигляду лінійної регресії:

2. Визначитися 3 розмірністю або порядком моделі (встановлення кількості внутрішніх змінних моделі). Для цього варто розглянути коваріаційні (залежність від характеристик випадкових перешкод) та кореляційні (взаємозв'язок між певними двома внутрішніми змінними) матриці. Існує кілька методів дослідження коваріаційних і кореляційних матриць, які дозволяють встановити недостатність або надмірність моделі.

3. Перейти до параметричної ідентифікації (спосіб параметризації моделі).

Дані для розроблення моделі можуть бути отримані в результаті пасивного або активного експерименту. В ході пасивного експерименту дослідник не впливає на хід досліджуваного процесу. Усі зміни параметрів процесу обумовлені або випадковими збуреннями, або технологічним регламентом процесу. При активному експерименті дослідник планує зміни хода технологічного процесу в програмі експерименту. У результаті активного експерименту спрощується процедура ідентифікації, але його проведення не завжди можливо. Для вибору класу моделі спочатку визначаються параметри моделі $\mathrm{F}=(\mathrm{L}, \mathrm{H}$, M) , де L - лінійність, $\mathrm{H}$ - безперервність, M багатомірність. Кожний із цих параметрів може приймати значення або 0 , або 1 . Найпростіша модель - F $=(1,1,0)$. Для ідентифікації моделі будуються критерії згоди. Найчастіше застосовують метод найменших квадратів. Метод найменших квадратів полягає в наступному. Нехай у результаті досліджень одержали деяку множину статистичних даних або даних експериментів. Якщо в якості аргументу виступає час, то маємо динамічний ряд [10]. Треба знайти аналітичний вигляд функції у = f(x), яка добре відображала б залежність між цими одержаними даними. Функцію у $=\mathrm{f}(\mathrm{x})$ можна шукати у вигляді інтерполяційного поліному. Але інтерполяційні поліноми не завжди добре відображають характер поведінки функції, що задана таблицею. До того ж значення у дістають у результаті експерименту, а вони, як правило, сумнівні. У цьому разі задача інтерполювання табличної функції втрачає сенс. Тому шукають таку функцію у $=\mathrm{F}(\mathrm{x})$, значення якої при $\mathrm{x}=\mathrm{x}_{\mathrm{i}}$ досить близькі до табличних значень у $(\mathrm{I}=1,2, \ldots, \mathrm{n})$. Формулу $\mathrm{y}=\mathrm{F}(\mathrm{x})$ називають емпіричною, або рівнянням регресії у на $\mathrm{x}$ . Емпіричні формули мають велике практичне значення. Вдало підібрана емпірична формула дає змогу не тільки апроксимувати сукупність експериментальних даних, «згладжуючи» значення величини $y$, а й екстраполювати знайдену залежність на інші проміжки значень х.

Процес побудови емпіричних формул складається 3 двох етапів: встановлення загального вигляду цієї формули і визначення найкращих іiі параметрів. Щоб встановити вигляд емпіричної формули, на площині будують точки 3 координатами ( $\left.\mathrm{x}_{\mathrm{i}}, \mathrm{y}.\right)$, 
$(\mathrm{z}=1,2, \ldots, \mathrm{n})$. Деякі з цих точок сполучають плавною кривою, яку проводять так, щоб вона проходила якомога ближче до всіх даних точок. Після цього візуально визначають, графік якої з відомих нам функцій найкраще підходить до побудованої кривої. Зазвичай, намагаються підібрати найпростіші функції: лінійну, квадратичну, дробово-раціональну, степеневу, показову, логарифмічну. Встановивши вигляд емпіричної формули, треба знайти ії параметри (коефіцієнти). Метод найменших квадратів не потребує жодної апріорної інформації. На практиці для моделювання динамічних систем як правило використовують лінійні динамічні стаціонарні моделі [2 - 9]. Р. Калманом було визначено такі властивості системи, як керованість, спостережуваність та ідентифікованість. Лінійна динамічна система називається повністю ідентифікованою по стану, якщо при заданому векторі початкових умов х існує керування, при якому параметри А , В , С можна відновити з точністю до параметрів їі канонічної форми (спостережуваності) за часовою послідовністю $\mathrm{x}=\mathrm{x}(\mathrm{t})$. Інакше, пара $\left((\mathrm{A}, \mathrm{B}, \mathrm{C}), \mathrm{x}_{0}\right)$ цілком ідентифікована тоді й тільки тоді, коли існує керування, при якому безліч пар, об'єднаних спільністю інтегральної кривої $\mathrm{x}=\mathrm{x}(\mathrm{t})$, вироджується при канонічному її описі в точку.

\section{Висновки}

Надано огляд сучасних інтелектуальних методів моделювання технологічних об'єктів, роль і місце моделей та моделювання, класифікацію моделей, підходи до розробки моделей. Наведено аналіз можливості застосування різноманітних видів математичних моделей для розв'язання задач оптимізації технологічних процесів промисловості. Показано для розв'язання яких задач доцільно використовувати саме детерміновані математичні моделі, а для яких - експериментально-статистичні.

\section{СПИСОК ЛІТЕРАТУРИ}

1. Математичне моделювання технологічних об’єктів: Підручник. / О.Б. Целіщев, П.Й. Єлісєєв, М.Г. Лорія, І.І. Захаров.- Луганськ: Вид-во Східноукр. нац. ун-ту. - 2011. - 421 с.

2. Черноруцкий И.Г. Методы оптимизации в теории управления: учебное пособие / И.Г. Черноруцкий. — СПб.: Питер, 2004. - $256 \mathrm{c}$.

3. Стенцель Й.І. Математичне моделювання технологічних об'єктів керування. - К.: ІСДО, 1993. - 328 с.

4. Johnson M.A. PID Control. New Identifications and Design Methods / M.A. Johnson, M.H. Moradi. - London: Springer, 2005. $-544 \mathrm{p}$.

5. Дьяконов В.П. Mathcad 11,12,13 в математике / В. П. Дьяконов. - М.: Горячая линия - Телеком, 2007. - 958 с.

6. Дорф Р. Современные системы управления/ Р. Дорф, Р. Бишоп. - М.: Лаборатория Базовых Знаний, 2002. - 832 с.

7. Іванов А.О. Теорія автоматичного керування: Підручник / А.О. Іванов. - Дніпропетровськ: Національний гірничий університет. $-2003 .-250$ с.

8. Теорія автоматичного керування / Л.М. Артюшин, О.А. Машков, Б.В. Дурняк, М.С. Сівов. - Львів: УАД, 2004.- 272 с.

9. Алексеев А.А. Идентификация и диагностика систем: учеб. для студ. высш. учеб. заведений / А.А. Алексеев, Ю.А. Кораблев, М.Ю. Шестопалов. - М.: Издательский центр «Академия», 2009. - 352 с.

10. Стенцель Й.І. Ідентифікація та математичне моделювання / Й.І. Стенцель - Луганськ: Вид-во Східноукр. нац. ун-ту. $-1995 .-247$ c.

Received (Надійшла) 11.12.2020

Accepted for publication (Прийнята до друку) 10.02.2021

\section{Modern intellectual methods of modeling complex technological objects}

$$
\text { L. Lievi, O. Zyma }
$$

Abstract. One of the key issues in the synthesis of automatic control systems is the development of adequate mathematical models of control objects. Development of models of physical systems is a very complex and time-consuming work, which takes from 80 to $90 \%$ of the effort required for the analysis and synthesis of control systems and includes the following stages: determining the process parameters that affect the object of control; determination of connections between parameters; drawing up material and energy balances of control objects; linearization of these balances; obtaining a differential equation. The result of modeling of almost all technological objects is a complex differential equation of large order, which is then used to calculate automatic control systems. A mathematical model is usually understood as a set of relations (equations, logical conditions, operators, etc.) that determine the characteristics of the states of the modeling object. Modern science and technology as objects of study consider the material objects of the surrounding world and their physico-chemical transformations. The practical implementation of these studies from laboratory installations to industrial production uses modeling as a process of cognition, as well as for optimal organization, operation, and management of production. Modern technologies are characterized by high complexity, which is manifested in the large number and variety of parameters that determine the course of processes, internal relationships between parameters, their mutual influence, and the change of one parameter can cause nonlinear change of other parameters. This complexity is exacerbated by the occurrence of multiple feedbacks between parameters, as well as uncontrolled perturbations randomly distributed over time. The information potential generated by technological processes is extremely large. With limited perceptions, it is necessary to reduce this potential, which will ultimately lead to a reduction in alternatives when making management decisions. This is achieved by knowing the process through models - simplified systems that reflect individual, limited in the right direction, aspects of the process under consideration. There are many ways to obtain models of technological processes. Each method makes it possible to build a model that is adequate to the process in a sense, depending on the chosen criterion. This means that there is some abstract correspondence between the set of models and the modeled object. The simulation, in fact, is based on the use of a dynamic analogy, which means a non-identical similarity of properties or relations.

Keywords: deterministic models, stochastic models, structural identification, parametric identification, passive experiment, active experiment. 